\title{
Amparo, proceso urgente
}

\section{Por Guillermo Adrían Perman}

\section{Resumen}

El presente trabajo tiene por objeto el desarrollo e investigación de la acción de amparo que ha sido receptada en nuestra Carta Magna desde el año 1994, y en leyes de cada jurisdicción respectiva.

A fin de abordar la conclusión final, se requiere del estudio de doctrina y jurisprudencia que han orientado el sentido de la vía en distintas corrientes.

Vemos que, por un lado, se inclinan los que analizan de manera estricta el curso de la vía del amparo, requiriendo para su procedencia: demostrar por parte del accionante la ineficacia de los remedios ordinarios administrativos y/o judiciales, independientemente del derecho de fondo que se trate, quedando claro que -en este sentido- se entiende la acción como excepcional. Mientras que por otro lado, los de una postura más amplia. Los que no entienden a la acción de amparo como una vía de excepción, sino una vía como posible elección del amparista, ponderando el derecho constitucional que se alega violentado, y la irreparabilidad del daño denunciado que requiere de un trámite procesal expedito y rápido.

Por ello, el presente estudio requiere del análisis merecedor por parte de quien se encuentra en posición de juzgar, vale decir: minucioso, pertinente, prudente y correspondiente a los derechos en juego, atento que no debemos soslayar que la recepción constitucional de la vía lo es a fin de no tornar la vigencia de los derechos y garantías constitucionales en una simple recepción de palabras en la nuestra Carta Magna, sino en vigencia de la realidad social.

\section{Introducción}

El tema elegido tiene por objeto la investigación, estudio y desarrollo de doctrina y antecedentes casuísticos respecto del instituto procesal de: "acción de amparo", todo ello, en razón de la importancia -a mi criterio- de establecer conclusiones en cuanto a su aplicación en la realidad de elección de vías procesales, ponderando la urgencia, tanto de los juzgadores como de los interesados, a la hora del inicio de planteos judiciales persiguiendo el restablecimiento de determinados derechos constitucionales que se endilguen violentados. 
Cabe traer al presente estudio tanto la normativa aplicable, jurisprudencia y doctrina, y elaborar -consecuentemente- conclusiones que sirvan de basamento para el intento de la vía propuesta y su consecuente procedencia, teniendo en cuenta los antecedentes de nuestros Tribunales y especialistas en la materia, sin dejar de soslayar el texto mismo tanto de la Constitución Nacional como de la normativa aplicable, en cuanto a su procedencia estipulan requisitos de viabilidad de la acción de amparo.

A su vez, entiendo por demás importante citar en el presente trabajo fallos que receptan derechos personalísimos reconocidos constitucionalmente y en tratados internacionales de la materia, por ejemplo, el derecho a la salud -derivación del derecho a la vida; todo ello, en razón al análisis minucioso que los juzgadores deben efectuar a la hora de las presentaciones mediante vía de amparo que se les inste, ponderando -como propuesta de estudio- el derecho de fondo que se trate, merecedor de incoarse a su respecto la acción de amparo, por las características de expedición y rapidez que califican dicha vía.

\section{Desarrollo}

Considero, para el inicio de este estudio, y como primigenia estructura metódica, traer el texto de nuestra Carta Magna; artículo 43 que reza:

Toda persona puede interponer acción expedita y rápida de amparo, siempre que no exista otro medio judicial más idóneo, contra todo acto u omisión de autoridades públicas o de particulares, que en forma actual o inminente lesione, restrinja, altere o amenace, con arbitrariedad o ilegalidad manifiesta, derechos y garantías reconocidos por esta Constitución, un tratado o una ley. En el caso, el juez podrá declarar la inconstitucionalidad de la norma en que se funde el acto $\mathrm{u}$ omisión lesiva. Podrán interponer esta acción contra cualquier forma de discriminación y en lo relativo a los derechos que protegen al ambiente, a la competencia, al usuario y al consumidor, así como a los derechos de incidencia colectiva en general, el afectado, el defensor del pueblo y las asociaciones que propendan a esos fines, registradas conforme a la ley, la que determinará los requisitos y formas de su organización:

Toda persona podrá interponer esta acción para tomar conocimiento de los datos a ella referidos y de su finalidad, que consten en registros o bancos de datos públicos, o los privados destinados a proveer informes, y en caso de falsedad o discriminación, para exigir la supresión, rectificación, confidencialidad o actualización de aquéllos. No podrá afectarse el secreto de las fuentes de información periodística. Cuando el derecho lesionado, restringido, alterado o amenazado fuera la libertad física, o en caso de agravamiento ilegítimo en la forma o condiciones de detención, o en el de desaparición forzada de personas, la acción de hábeas corpus podrá ser interpuesta por el 
afectado o por cualquiera en su favor y el juez resolverá de inmediato, aun durante la vigencia del estado de sitio (Constitución Nacional)

Sentado lo cual, deviene necesario valorizar lo expuesto por el constituyente en razón a los derechos en juego que se propende en el articulado en cuestión por parte del juzgador:

El examen a efectuar, requiere e implica -a mi entender-no sólo el análisis de los requisitos de admisibilidad, sino también las circunstancias fácticas de cada caso y la cuestión de fondo planteada.

Por ejemplo, el derecho a la salud -derivación del derecho a la vida-donde se encuentra en juego el estado físico y psíquico de una persona, no cabría considerar necesario el agotamiento de la vía para habilitar la instancia judicial de manera taxativa, teniendo en cuenta las circunstancias de hecho, claro está.

En ese sentido, exigirse el agotamiento de la vía administrativa, dilataría de modo innecesario el goce de sus derechos constitucionales protegidos provincial, nacional y supranacionalmente (artículo 36, apartado 8 Constitución de la Provincia de Buenos Aires, reconocidos implícitamente en los artículos 32 y 43 de la Constitución Nacional; artículo 12 del Pacto Internacional de Derechos Económicos Sociales y Culturales) por los cuales se insta la garantía procesal del amparo.

En este punto, y atento las particularidades en casos de afectaciones de salud, considero que el requisito de continuar con la tramitación administrativa debe ser ponderado "cuando los perjuicios sean de tal magnitud que sería ilusoria la reparación posterior que podría obtenerse por las acciones y procedimientos ordinarios" (Serró, 2000: 399). En efecto, "El requisito de la inexistencia de otra vía legal hábil para reparar el agravio no tiene vigencia absoluta porque de existir un daño grave e irreparable, éste es suficientemente operante para que, desplazando la exigencia antedicha, la acción de amparo encuentre eco judicial" (STJ, 1987).

En el marco propuesto, destaco que mi objetivo deviene en analizar la acogida favorable de estas vías intentadas en tantos casos, que algunos defienden su elección sólo para casos urgentes y excepcionales, mientras que otros, que resulta una creación normativa para la defensa inmediata de un derecho constitucional conculcado, en beneficio de la celeridad (amparo) o un derecho que aparentemente le asiste al solicitante (caso de la medida cautelar). Ha dicho la Suprema Corte de Justicia de la Provincia de Buenos Aires que: "Corresponde que los jueces restablezcan de inmediato el derecho restringido por la rápida vía del amparo cuando la remisión del examen de la cuestión a los procedimientos ordinarios, administrativos o judiciales, pudiera causar un daño grave e irreparable" (SCBA, 1994). 


\section{Legislación nacional y normativa aplicable (en general)}

\section{Ley $\mathrm{n}^{\circ} 16.986$}

1. La acción de amparo será admisible contra todo acto u omisión de autoridad pública que, en forma actual o inminente, lesione, restrinja altere o amenace, con arbitrariedad o ilegalidad manifiesta los derechos o garantías explícita o implícitamente reconocidas por la Constitución Nacional, con excepción de la libertad individual tutelada por el "hábeas corpus". 2. La acción de amparo no será admisible cuando: a) Existan recursos o remedios judiciales o administrativos que permitan obtener la protección del derecho o garantía constitucional de que se trate; b) El acto impugnado emanará de un órgano del Poder Judicial o haya sido adoptado por expresa aplicación de la ley 16970; c) La intervención judicial comprometiera directa o indirectamente la regularidad, continuidad y eficacia de la prestación de un servicio público, o el desenvolvimiento de actividades esenciales del Estado; d) La determinación de la eventual invalidez del acto requiriese una mayor amplitud de debate o de prueba o la declaración de inconstitucionalidad de leyes, decretos u ordenanzas; e) La demanda no hubiese sido presentada dentro de los 15 días hábiles, a partir de la fecha en que el acto fue ejecutado o debió producirse.

\section{Código Procesal Civil y Comercial de la Nación}

Artículo 321: Será aplicable el procedimiento establecido en el artículo 498:...

20) Cuando se reclamase contra un acto u omisión de un particular que, en forma actual o inminente, lesione, restrinja, altere o amenace con arbitrariedad o ilegalidad manifiesta algún derecho o garantía explícita o implícitamente reconocidos por la Constitución Nacional, siempre que fuere necesaria la reparación urgente del perjuicio o la cesación inmediata de los efectos del acto, y la cuestión, por su naturaleza, no deba sustanciarse por alguno de los procesos establecidos por este Código u otras leyes.

\section{Utilización de la vía}

Al respecto, debe tenerse presente que la acción de amparo constituye un remedio de carácter excepcional, por lo tanto su utilización está sólo reservada para aquellos supuestos en que no existan otras vías legales aptas para proteger los derechos constitucionales conculcados por actos $\mathrm{u}$ omisiones de particulares $\mathrm{o}$ de órganos del Estado. De allí que para la procedencia de esta acción se requieren circunstancias muy particulares, caracterizadas por la arbitrariedad o ilegalidad manifiesta y la demostración de que 
el daño grave sólo puede ser reparado acudiendo a la vía urgente y expedita de este tipo de proceso (Gozaini, 2004: 314).

Se ha expedido la jurisprudencia, en torno a la consideración de derechos constitucionales en juego. Con fecha 8 de febrero de 2010, en la causa caratulada "Pueblo S.R.L Y Otros C/ Provincia De Buenos Aires Y Otros S/ Amparo", la Cámara de Apelación en lo Contencioso Administrativo con asiento en San Martín (provincia de Buenos Aires) confirmó la sentencia que rechazó in limine la acción de amparo que cuestionaba la restricción del horario de cierre locales bailables, los límites de admisión y los límites en el expendio de bebidas alcohólicas, con fundamento en que tales restricciones, establecidas por la ley 14.050, no constituyen una afectación constitucional de los derechos de comerciar, ejercer industria lícita, de propiedad y de igualdad.

\section{Comprensión del instituto}

Tenemos que, por un lado, lo que concierne a una medida expeditiva como la "cautelar":

(...) la doctrina procesal mundial ha ido receptando diversos institutos que, unidos a los ya existentes, buscan satisfacer las demandas de una justicia moderna, ágil y eficaz. A ese respecto se ha centrado el objetivo en la reformulación del proceso cautelar a fin de hacer realidad aquí y ahora la tutela jurídica buscada, logrando así la satisfacción efectiva de los verdaderos fines del derecho (Peyrano, 1997:226)

Ahora bien, en lo que a la vía del amparo, se ha dicho que: "La acción de amparo constituye una vía excepcional, que sólo procede contra todo acto $\mathrm{u}$ omisión de autoridad pública que amenace con arbitrariedad o ilegalidad manifiesta los derechos o garantías reconocidos por la Constitución Nacional, en ausencia de otro medio adecuado, o cuando la inminencia del daño hiciera ilusoria su reparación ( CNPen. Econ, 1994). [...] "Ante la existencia de dudas sobre la admisibilidad de la acción de amparo debe darse curso al trámite respectivo, porque lo definitorio radica en analizar si la vía del amparo es la específica para la adecuada, oportuna y eficaz defensa de los derechos invocados, según las circunstancias particulares de cada caso" (CNCiv, 2002: 266).

Sentado lo precedente, cabe reiterar los conceptos vertidos con anterioridad, aunque con diversos matices que hacen a la vía excepcional en estudio, es decir, y a mi criterio, debemos analizar en conjunto el tema procesal -ritual-y de fondo en cada caso en concreto que se inicie, valorando si los derechos en juego tienen entidad tal que merecen tramitar por la presente vía, con la rapidez que lo caracteriza, soslayando de ese modo, los trámites que acarrearía un proceso ordinario, con la producción de prueba que llevaría, los plazos pertinentes, etc., 
todo ello, en consonancia a lo que la doctrina jurisprudencial ha reflejado (ver lo detallado supra).

Comprendiendo ello, no debo pasar por alto un principio protectorio del derecho constitucional de acceso a la justicia, "in dubio pro actione", ello nos lleva a que en caso de duda sobre la viabilidad de la acción de amparo por sobre las vías ordinarias, debe estarse a tener que resolver sobre la admisión formal del amparo, sin perjuicio de las consideraciones particulares de cada cuestión, teniendo en cuenta la irreparabilidad del daño denunciado, junto con el carácter excepcional de la vía.

Ya la Corte Suprema de Justicia Nacional ha dicho:

La acción de amparo constituye un remedio de excepción, cuya utilización está reservada para aquellos casos en que la carencia de otras vías legales aptas para resolverlas pueda afectar derechos constitucionales, máxime cuando su apertura requiere circunstancias muy particulares, caracterizadas por la existencia de arbitrariedad o ilegalidad manifiesta, y la demostración, por añadidura, de que el daño concreto y grave ocasionado sólo puede eventualmente ser reparado acudiendo a la vía urgente y expedita del citado proceso constitucional " (CSJN, 1994).

Ello, teniendo en cuenta los presupuestos desarrollados anteriormente juntamente con los criterios que la doctrina y la jurisprudencia exponen.

Esta acción constitucional de amparo no desplaza a ningún carril adjetivo, sino que socorre al sistema, cuando éste exterioriza la ausencia de uno, adecuado al objeto de la pretensión.

Más allá de las diversas inquietudes que giran en torno a su regulación y optimización, nadie duda de la ventaja de contar con el amparo, ni de cuanto nos ha permitido lograr en protección de derechos fundamentales consagrados en nuestra Carta Magna, por ejemplo, respecto de derechos personalísimos como la salud y la vida, derechos que se consideraban implícitos y se enfatizaron a partir de la reforma constitucional de 1994, especialmente del art. 42 y del art. 75 inc. 22, que otorgó jerarquía constitucional a los tratados internacionales sobre derechos humanos, afianzando la primacía de la persona, entre muchas otras cuestiones.

Como también contar con medidas como la autosatisfactiva, que:

(...) atento a que su despacho se requiere en forma inmediata y definitiva, por imperio de las circunstancias fácticas que se denuncian, se impondrá sin previa audiencia del afectado, sin perjuicio de que, en casos excepcionales y cuando el marco de situación lo permita, el juez podrá arbitrar un sumarísimo y expeditivo trámite o audiencia previa, todo librado al prudente 
criterio del juzgador cuidando de no terminar desbaratando el objetivo y fin mismo de la medida (CSJN, 1994).

\section{Análisis de la vía}

La lectura de la doctrina y jurisprudencia me ha generado la convicción de establecer un equilibrio entre los pensadores que entienden o se inclinan por considerar a la acción de amparo una vía puramente excepcional, y los que iteran que esta vía debe prosperar cada vez que se cree vulnerado un derecho constitucional, independientemente de las circunstancias o urgencias del caso.

$\mathrm{Al}$ respecto, comenta Alberto Sánchez, que la Corte Federal, sostuvo que:

(...) cabe aquí recordar que esta Corte, a poco de regir el nuevo texto del art. $43 \mathrm{CN}$, en fallo dictado en fecha 4-3-1996, ya interpretó esa disposición en el sentido de que mantenía vigente el requisito de la irreparabilidad del perjuicio que se invoca por vías distintas al amparo, dejando sentado que tal requisito constituía un presupuesto de admisibilidad de la acción. Se dijo allí que tal conclusión se fundaba en que cuando el constituyente condicionó la viabilidad de la acción expedita y rápida del amparo al hecho de que no exista otro medio judicial más idóneo, utilizó el vocablo idóneo en el sentido jurídico de hábil o eficaz..." [...] (...) constituye condición de viabilidad de la acción de amparo que el interesado acredite que no tiene opción por otras vías procesales más adecuadas, apropiadas, aptas para lograr la restitución del derecho constitucional que se dice menoscabado (Cassagne, 2007: 281).

La referencia al medio judicial más idóneo aduce a uno de los requisitos de admisibilidad, entidad tal del instituto que podría conllevar el rechazo in limine de la acción de amparo incoada o la prosperidad de la vía.

Y retomando el acuse de menoscabo a un derecho constitucional, el mismo depara, de acuerdo a su entidad y basamento jurídico-fáctico, aquel análisis de los estudiosos del caso, sea el Juez, la Doctrina, los litigantes, etc., que deben elaborar -en pos de clarificar el sentido del carril elegido- un criterio netamente objetivo equilibrando las distintas corrientes esgrimidas ut supra.

El artículo $43^{\circ}$ de la Constitución Nacional reformada establece que toda persona puede interponer acción expedita y rápida de amparo, siempre que no exista otro medio judicial más idóneo. Considero procedente la vía elegida ello pues siempre que aparezca de manera clara y manifiesta la ilegitimidad de una restricción cualquiera a alguno de los derechos esenciales de las personas, así como el daño grave e irreparable que causaría remitiendo el examen de la cuestión a los procedimientos administrativos o judiciales, corresponderá que los jueces restablezcan de inmediato el derecho restringido por la vía rápida del amparo . 
Se trata de un precepto claro que no ofrece duda para su interpretación: frente a un derecho cierto afectado o amenazado por conducta manifiestamente divorciada del ordenamiento jurídico, la Constitución Nacional otorga el amparo siempre, salvo que exista otro medio judicial aún más expedito y rápido que ése, en cuyo caso la vía amparista no se admite (Rivas,1994:633).

Ello es así pues siempre que aparezca de manera clara y manifiesta la ilegitimidad de una restricción cualquiera a alguno de los derechos esenciales de las personas, así como el daño grave e irreparable que causaría remitiendo el examen de la cuestión a los procedimientos administrativos o judiciales, corresponderá que los jueces restablezcan de inmediato el derecho restringido por la vía rápida del amparo (Fallos:241:291; 280:228; 306:400).

Se trata de una acción "expedita y rápida" cuya justificación se deriva de la naturaleza de los derechos en juego; vale decir, la acción de amparo debe posibilitar un proceso rápido y una respuesta judicial adecuada y en tiempo oportuno. Es por ello que el art. 43 alude: "... siempre que no exista otro medio judicial más idóneo...".

Así, en jurisprudencia (Emigen S.A. c/Municipalidad de La Matanza s/amparo), la Dra. Laura Monti expuso:

(...) considero que no se encuentran reunidos en autos los requisitos exigidos para la procedencia de la excepcional vía intentada, en particular, como lo señaló el juez de primera instancia, en lo que respecta a la existencia de otras vías idóneas, a fin de proteger -sin daño grave o irreparable- los derechos que el recurrente entiende afectados.

Sobre el punto cabe sostener, en primer lugar, que el art. 20, inc. $2^{\circ}$ de la Constitución Provincial establece que el amparo procederá siempre que no pudieren utilizarse, por la naturaleza del caso, los remedios ordinarios sin daño grave o irreparable.

Por su parte, el art. 43 de la Constitución Nacional prevé, en lo que interesa, que toda persona puede interponer acción expedita y rápida de amparo, siempre que no exista otro medio judicial más idóneo.

A su turno, la ley 7166 dispone que "la acción de amparo sólo procederá cuando no existan otros procedimientos ordinarios administrativos o judiciales, que permitan obtener el mismo efecto" (art. 2o).

Sobre la base de lo dispuesto en estas normas considero que el amparista, a fin de obtener la protección de los derechos que entiende que han sido conculcados, cuenta con las vías legales ordinarias pertinentes (conf. Código Contencioso Administrativo de 
la Provincia de Buenos Aires, aprobado por la ley 12.008) que resultan más idóneas que la excepcional acción de amparo.

La alegada demora de los trámites ordinarios no resulta argumento suficiente para revertir lo decidido en este aspecto, toda vez que es reiterada la jurisprudencia de la Corte Suprema de Justicia de la Nación en el sentido de que esta vía excepcional debe descartarse ".... no sólo para obviar los trámites legales aptos sino también para urgirlos" (Fallos: 311:612; en análogo sentido, Fallos: 311: 2319;313:433).

\section{Procedencia}

La acción de amparo, destinada a asegurar la plena vigencia de la Constitución Nacional, no introduce alteración en el orden legal de las competencias, doctrina recibida por el art. 2 inc. a) de la Ley 16.986. En consecuencia, la falta, el abandono o la suspensión del ejercicio de las acciones y recursos regulados por las leyes procesales para la defensa de derechos constituyen impedimentos sustanciales para la viabilidad del amparo. Por la vía excepcional del amparo no se pueden obviar las debidas instancias ordinarias administrativas o judiciales, salvo que queden acreditadas su ineptitud o ineficiencia para dilucidar el planteo. Los jueces no están facultados para evitar las posibles demoras de aquéllas autorizando otras que consideran más convenientes y expeditivas, ya que la demanda de amparo no altera las instituciones vigentes. La norma del art. 2 inc. d) de la ley 16.986 establece que el amparo es improcedente cuando la determinación de la eventual invalidez del acto requiere una mayor amplitud de debate o prueba (Cartaña, 1991).

La Cámara de Apelación en lo Contencioso Administrativo de Gral. San Martín (provincia de Buenos Aires) ha dicho que:

En cuanto al carácter excepcional del remedio jurisdiccional intentado, cabe recordar que la Corte Suprema de Justicia de la Nación ha señalado que:

(...) La acción de amparo es un proceso de índole excepcional reservado para aquellas situaciones extremas en las que la carencia de otras vías legales aptas para zanjarlas pudiera afectar derechos constitucionales, y su viabilidad requiere, por consiguiente, circunstancias muy particulares caracterizadas por la existencia de arbitrariedad o ilegalidad manifiestas y la demostración, por añadidura, de que el daño concreto y grave ocasionado sólo puede eventualmente ser reparado acudiendo a la acción urgente y expeditiva del amparo; razones del mismo orden conducen a descartar su utilización no sólo para obviar los trámites legales aptos sino también para urgirlos (Fallos: 311:612; en análogo sentido, Fallos: 311: 2319; 313:433). 
En idéntico orden de ideas, se ha indicado que resulta "necesario acreditar la ineficacia de los procedimientos ordinarios y un agravio irreparable derivado de su utilización, para que la vía excepcional del amparo sea admisible" (Fallos: 311:1357) y que la alegada "demora" del trámite ordinario "....no constituye, sin más, un argumento que justifique la procedencia de la vía sumarísima del amparo" (Fallos: 308:2068).

"La alegada existencia de agravios a derechos constitucionales no justifica la demanda de amparo, si en el ordenamiento jurídico vigente existen acciones para su debida tutela, que constituyen vía apta para la salvaguarda del interés comprometido" (Fallos: 310: 1548).

Tan disimiles criterios existen entre la jurisprudencia así como la doctrina, lo que parece, y me lleva al interés del presente estudio, no se ha receptado en la práctica con pacífico fin, el carril procesal del amparo, en la forma propuesta por el constituyente en la última reforma de 1994.

Se presentan discusiones sobre la factibilidad de un amplio debate de prueba para el caso concreto, lo que en fin llevaría al rechazo de la acción de amparo intentada, ya que su contenido no prevé aquel, sino un carril rápido, expedito, que intenta compensar ese menoscabo al derecho constitucional que se endilga conculcado.

Vale recordar que tras la reforma constitucional de 1994, en que se le asignó status constitucional a la acción de amparo, ésta no ha perdido su carácter de remedio excepcional. Así, se ha dicho que "...según conocida jurisprudencia de este Tribunal, resulta indispensable para la admisión del remedio excepcional del amparo que quien solicita la protección judicial demuestre, en debida forma, la inexistencia de otras vías legales idóneas para la protección del derecho lesionado o que la remisión a ellas produzca un gravamen no susceptible de reparación ulterior (Villar, Carlos Alfredo c/ Banco Central de la República Argentina s/ amparo).

No quiero soslayar las exposiciones sentadas por la CSJN en el caso "Peralta", donde sostuvo que aun siendo el amparo un remedio excepcional y no absoluto, permitía a cualquier tribunal que advirtiera el quebramiento de una ley, decreto $\mathrm{u}$ ordenanza restablecer de inmediato su plena vigencia, aun frente al obstáculo de la ley reglamentaria. Ello así, por el artículo $2^{\circ}$ inc. $\mathrm{D}$ de la Ley $\mathrm{n}^{\circ} 16.986$, se debe interpretar como un medio razonable concebido para evitar que la acción de amparo sea utilizada caprichosamente con el propósito de impedir la efectiva vigencia de las leyes y reglamentos dictados en virtud de lo que la Constitución dispone, pero no como un sistema tendiente a paralizar los fines que la ley promete, cuando el acto de autoridad arbitrariamente se fundamente en normas que resultan palmariamente contrarias al espíritu y letra de las normas.

También, se ha establecido que: "El amparo es un proceso excepcional que resulta apto sólo frente a situaciones extremas y delicadas, ante las cuales la ineficacia de otros procedimientos originan un daño concreto y sólo reparable por 
esta vía." (...) "La existencia de remedios procesales ordinarios excluye la procedencia de la acción de amparo, siendo insuficiente a ese fin el perjuicio que pueda ocasionar la dilación de los procedimientos corrientes, extremo que no importa más que la situación común de toda persona que peticiona mediante ellos el reconocimiento de sus derechos." (Entre Ríos, Provincia de y otro c/ Estado Nacional Secretaría de Energía-s/ Acción de Amparo).

La doctrina sobre el alcance y el carácter de esta vía excepcional no ha sido alterada por la Reforma Constitucional de 1994, al incluirla en el art. 43, pues cuando éste dispone que "toda persona puede interponer acción expedita y rápida de amparo, siempre que no exista otro remedio judicial más idóneo”, mantiene el criterio de excluir dicha vía en los casos que por sus circunstancias requieran mayor debate y prueba y, por tanto, sin que se configure la "arbitrariedad o ilegalidad manifiesta” en la afectación de los derechos y garantías constitucionales, requisitos cuya demostración, como se dijo, es imprescindible para la procedencia de esa acción (fallos: 306/788, 319/2955 y 323/1825, entre otros).

Gozaíni ha expresado que

(...) se debe evitar que el amparo continúe siendo visto como un proceso excepcional y extraordinario, pues la esencia de su mensaje es la protección inmediata (amparar) y efectiva, contra cualquier amenaza o lesión a un derecho fundamental. La continuidad del amparo-proceso sirve como excusa para evitar el juzgamiento, mientras que el derecho al amparo logra asegurar ese cauce mencionado para la tutela efectiva de los derecho humanos (Gozaíni, 2004: 314).

Se desprende de su criterio, una corriente que cede a la exigencia ritual y específica de los requisitos que la misma Constitución expresa; con lo cual, sin dejar de lado la importancia jurídica de los conceptos vertidos por este doctrinario, intento por el presente estudio, no soslayar tanto el mecanismo de amparo propuesto constitucionalmente, como una "garantía procesal", juntamente con los derechos en juego en cada caso que merezcan el curso de trámite urgente, ya que, de lo contrario, perdería virtualidad jurídica- procesal, tanto la acción de amparo, como el resto de los procesos ordinarios y extraordinarios preceptos en la normativa vigente, y valorados por el Juzgador a la hora de analizar la admisibilidad formal de los mismos.

Postula Gozaíni su criterio diciendo: “...la promesa esencial del amparo-proceso consiste en habilitar una vía contenciosa que haga justiciable a la misma Constitución, tanto en los derechos que otorga como pilares para los derechos del hombre, como la idea de lograr que ella misma se supere con la evolución de la sociedad" (Gozaíni, 2004: 314).

Cabe traer a colación las menciones sobre la procedencia de la acción de amparo cuando, aún existiendo otros medios legales ordinarios, ellos no tengan la autoridad suficiente para subsanar la violación de los derechos que se necesita, de 
modo que el rechazo de la vía de amparo incoada, y llevar al aspirante a los carriles ordinarios, resultaría provocar un riesgo que el amparo podría evitar.

Por ello, trato a su vez de ponderar que cuando según las circunstancias del caso merezca un proceso rápido y expedito, la acción de amparo se convierte en una verdadera "garantía procesal", aquella consagrada y acogida primeramente por la jurisprudencia (Siri, Angel s/ interpone recurso de hábeas corpus), para luego receptarla la legislación nacional Ley $\mathrm{n}^{\circ} 16.986$, y la consagración definitiva en nuestra Constitución Nacional, artículo 43.

Vale la pena recordar así los orígenes de la presente acción, a su respecto, dice María Angélica Gelli que "En sus orígenes, la acción de amparo tuvo por principal efecto acelerar el dictado de las decisiones judiciales enderezadas a proteger a quienes sufrían una manifiesta violación de sus derechos constitucionales, en ausencia de remedios procesales adecuados para reparar aquella acción”; noto, la esencia del objetivo constituyente del año 1994, en cuanto prevé la aplicación del carril del amparo cuando los remedios judiciales ordinarios tornarían abstracto el pedido que conviene articular por una acción expedita y rápida como en el caso en estudio. En el mismo trabajo, expuso "...es posible asimilar al amparo -tal como fue aplicado por la Corte Suprema en los casos "Siri" y "Kot"- con los procedimientos de las courts of equity inglesas, en tanto las reglas procesales empleadas en esos procesos eran suficientemente flexibles como para admitir su adecuación al caso concreto. Se trataba, en suma, de suministrar por parte del Estado una respuesta jurisdiccional eficiente y concreta" (Gelli, 2008: 606).

Con ello, coincido plenamente con esta corriente doctrinaria, que explica una decisión, en concreto, del Estado, a través del órgano legislativo, que otorga la función-facultad al judicial, de tramitar por una vía especial y rápida casos que merezcan una rápida solución al derecho constitucional que se endilga violentado.

En la misma obra, explica la M. A. Gelli, respecto de los casos de la CSJN, "Siri" Fallos 239:459 (1957), y "Kot" Fallos 241:291 (1958), que en el primero procedió contra actos de autoridad pública y, el segundo, contra actos de particulares. No obstante, señala que en caso "Kot" la afectación del derecho provenía de la acción desarrollada por los miembros de un sindicato. En la sentencia, el Máximo Tribunal nacional, equiparó aquella acción proveniente de un sindicato a la fuerza estatal. Ambos fallos se dictaron en momentos particularmente críticos para el sistema institucional argentino, crisis que tuvo efectos directos sobre la estabilidad de la Corte Suprema. La primera de las sentencias fue emitida por mayoría de cuatro de los integrantes del Máximo Tribunal, designados por el gobierno militar del momento, y la segunda, también por mayoría con la disidencia de dos de los nuevos ministros nombrados por el presidente constitucional Arturo Frondizi -quien sucedió al gobernante de facto, general Aramburu- al iniciar, aquel, su mandato." (ob. Cit. Pág. 608).

Con los detallados antecedentes jurisprudenciales emanados de la Corte Federal, más allá de la distinción de uno y otro caso sobre contra quien procede la 
acción de amparo, "el legitimado pasivo", es decir, por ante un particular o autoridad pública, no puedo soslayar la esencia o fin que el Máximo Tribunal ponderó y consideró para que prospere una acción extraordinaria, ya que entendió, que recurrir a los medios judiciales ordinarios para la consecución de los fines para los cuales fue intentada la acción, tornaría la cuestión en dar una tardía respuesta al derecho constitucional conculcado, de modo que la acción de amparo mereció tal acogida.

En la obra precedentemente citada de Juan Carlos Cassagne (2007: 281), decía Mario Rejtman Farah que:

(...) De una concepción extremadamente ritualista, y además muchas veces incorporada y producida por una interpretación jurisprudencial restrictiva, se derivará necesariamente una denegación de justicia y un desamparo que en nada contribuye a la defensa de los derechos individuales que la Constitución confiere a la justicia. Introducir por vía de interpretación criterios selectivos para acceder a la justicia, rechazando in limine la acción, es probar de una cobertura adecuada a la defensa de los derechos individuales que el sistema jurídico se propone fortalecer. De lo que se trata es de formular técnicas y herramientas conceptuales que hagan viable la realización de esos intereses" (192).

De este modo, propongo por el presente estudio establecer ciertos parámetros de análisis a la hora, bien de decidir sobre los requisitos formales de admisibilidad de toda acción de amparo incoada, y en otro lado, los derechos constitucionales en juego.

En la característica especial de vía que se trate, se ha dicho: "La índole excepcional del amparo ha sido reiteradamente señalada por la Corte Suprema, en tanto es un proceso reservado para aquellas situaciones extremas en las que la carencia de otras vías legales aptas para zanjarlas pueda afectar derechos constitucionales. Su viabilidad requiere, por consiguiente, circunstancias muy particulares caracterizadas, entre otros aspectos, por la existencia de un daño concreto y grave que sólo pueda eventualmente ser reparado acudiendo a la acción urgente y expeditiva del amparo (CSJN- Fallos, 312:262). [...] La existencia de cauces ordinarios para discutir la cuestión que se plantea por vía del amparo no lleva, de por sí, al rechazo de la acción deducida, dado que, según lo normado en el art. 43 de la Const. Nacional, dichos procesos deben resultar más idóneos que la demanda de amparo (Iamp Medisur S.A. c/ Poder Ejecutivo Nacional-Ministerio de Obras y Servicios Públicos).

A su vez, y atendiendo al principio rector de in dubio pro actione, ha reflejado la jurisprudencia que "uno de los requisitos de la acción de amparo, es la inexistencia de vías ordinarias administrativas o judiciales, adecuadas para resguardar el derecho que se trate. Este principio cede cuando la remisión de la 
cuestión a aquellos procedimientos ordinarios, ocasionaría un daño grave o irreparable o cuando tal remisión constituya un ritualismo inútil" (Asociación de Trabajadores de la Universidad del Nordeste c. Resolución 4/84 de la Universidad Nacional del Nordeste).

El amparo no tiene por finalidad obviar o urgir el trámite de los procedimientos administrativos o judiciales previstos legal o reglamentariamente para el logro del resultado que con él se procura, ni resulta apto para autorizar a los jueces a irrumpir en asuntos ajenos a la jurisdicción que por ley tienen conferida, alterando el normal juego de las instituciones vigentes." (Bandieri, Atilio E).

(...) en lo referente a la pretensión de que el actor pruebe que la elección de otra vía que no sea el amparo le traería aparejado un daño irreparable, que aquella constituye un exceso frente a la contundente verosimilitud del derecho invocado; siendo que, por lo demás, una demostración como la requerida por la demandada escapa, por sus características, al carácter sumario del remedio impetrado (Revel, Hermes).

Se ha dicho:

(...) el amparo nunca fue claramente aceptado como remedio procesal legitimo para controlar la constitucionalidad de las leyes. En líneas generales, la ley 16.986 receptó la tendencia jurisprudencial trazada antes de su sanción, que admitía el planteo de inconstitucionalidad de las leyes, decretos u ordenanzas sólo, en principio, tal como se señalara en el citado caso "Outón" (Peralta).

En el mismo sentido, esta obra (Iamp Medisur S.A. c/ Poder Ejecutivo NacionalMinisterio de Obras y Servicios Públicos) recepta que:

(...) se decidió que la particular vía del amparo impide articular la declaración de inconstitucionalidad en abstracto si no resulta de la causa el planteo del supuesto concreto en el cual sea cierta o inminente la aplicación de la norma legal impugnada. En dicho caso, la improcedencia de la declaración de inconstitucionalidad está estrechamente vinculada con la inexistencia de "caso" requerido por la norma constitucional, más que con el hecho de que tal requerimiento se haya formulado en el ámbito procesal particularmente excepcional del amparo. [...] Lo cierto es que con la reforma de nuestra Ley Fundamental operad en 1994 se ha 
consagrado la facultad constitucional del juez de declarar la inconstitucionalidad de las normas, lo cual, insistimos, importa obviamente una potestad facultativa y no un deber. (pág. 172; 175/176).

Volviendo al análisis de requisitos de admisibilidad, en torno a la excepcionalidad de la vía, vemos (Hipermercado Jumbo, S.A c. Municipalidad de la Capital) que: "Si la indagación de las cuestiones fácticas invocadas requiere un adecuado debate y amplitud de prueba que el juicio de amparo no está en condiciones de proporcionar y que sólo puede lograrse en el marco adecuado de los procedimientos pertinentes, es un acierto la temprana desestimación de la acción promovida que no ha logrado provocar una distinta convicción en el Tribunal...”; aquí se rechazó in limine la acción de amparo contra la Ordenanza Municipal $n^{\circ} 39.925 / 84$, que impedía a los supermercados expender comestibles los días sábados y domingos y feriados durante las veinticuatro horas.

Por otra parte, en referencia a las alternativas de otras vías idóneas para el fin perseguido por el amparo, la jurisprudencia de la Corte Federal sentó que

(...) la existencia de vías ordinarias no obsta como principio a la utilización del amparo -el que será objeto de merito en cada caso en particular- Pero debe tenerse presente, que la acción de amparo es un recurso excepcional, que no permite su extensión a supuestos que encuentran efectivo resguardo al acceso judicial por los remedios procesales ordinarios. De lo contrario estaríamos desvirtuando no solo la egregia extirpe de esta garantía constitucional sino minando la riquísima variedad de vías procesales ordinarias que el avance científico del derecho procesal a permitido incorporar en nuestros códigos rituales positivos (CSJN T. 316).

Ponderó Vallefin (2006: 516) que: “...la amparización y/o cautelarización del ejercicio judicial atenta contra el fortalecimiento del proceso ordinario como vía procesal primaria, natural e idónea, y puede conducir al "desgobierno" del ejercicio tutelar judicial por dichos conductos."

Se ha señalado que "Dada la finalidad preventiva que también caracteriza a la acción de amparo no es necesario acreditar la existencia de un daño consumado para su procedencia: "... la procedencia de la demanda de amparo se halla supeditada a la inexistencia de vías legales aptas para la tutela del derecho que se dice vulnerado (Fallos 270:176 - La Ley, 131-528-; 300:1231). Por ser de trámite sumarísimo, no procede en el supuesto de cuestiones opinables, que requieren debate y prueba (Fallos 271: 165; 273:84; 281:394, 229, 185 -La Ley, 134-1106, fallo 20.497-S; 134-382; 146-45-). Ni es, en principio, la vía apta para obtener la 
declaración de inconstitucionalidad de leyes, decretos y ordenanzas (Fallos 274:79 La Ley, 135-858-). Reviste carácter excepcional y sólo procede en situaciones de imprescindible necesidad de ejercerla (Fallos 280:394; 301:1061).”

También Sagües (2007: 193) ha explicado que: "En el supuesto que la vía administrativa no atienda idóneamente al problema (es decir, si su trámite, por uno u otro motivo, no es lo suficientemente útil para proteger el derecho vulnerado y puede, por ende, ocasionar un gravamen irreparable), el interesado puede articular el amparo omisso medio, es decir, directamente."

Noto, conforme el presente estudio, dos corrientes ritualista:

Por un lado, la corriente que tiende a la viabilidad de la vía del amparo cuando algún derecho de índole constitucional sea vulnerado o potencialmente menoscabado, sin exigir para el caso, una estricta visión de cumplimiento y demostración que la vía elegida sea la única tendiente a proteger ese derecho invocado; -

Y por la otra, una corriente que liminarmente al análisis del derecho en juego, verifica la exigencia taxativa del cumplimiento de cado uno de los requisitos para la procedencia formal del amparo, tornando dicho carril muchas veces en abstracto, dejándolo únicamente viable para casos puramente excepcionales y extraordinarios, quizás -en este punto- alejado del sentido que el constituyente le dio en el dictado del artículo 43 de nuestra Carta Fundamental y de la Ley Nacional $n^{\circ} 16.986$.

A su vez, cabe mencionar la etapa de un proceso en la que propongo como estudio, esto es, la del análisis formal de la acción de amparo iniciada, sin adentrar en la cuestión de fondo invocada, pero, no soslayando el alcance de lo solicitado y el raingambre del derecho constitucional que se trate.

Por lo que, a la hora de estudiar el alcance de lo pretendido por el solicitante, deberá el Juez interviniente analizar la urgencia y rapidez de la proposición traída.

Evaluando los antecedentes referidos y doctrina desarrollada, concluyo, y como oportunamente esgrimí, entender los antecedentes jurisprudenciales de la acción de amparo, y observar que tanto los Tribunales inferiores como la doctrina de la Corte Federal han establecido en los fundamentos que comparto un criterio de admitir la vía del amparo para casos que revelen una asistencia y desarrollo procesal urgente, carácter básico de la acción de amparo.

Por ejemplo, en el caso del derecho a la salud, un derecho de raingambre constitucional, y que tiene recepción en numerosos casos jurisprudenciales, tanto en nuestra Corte Federal, Tribunales inferiores y doctrina especializada, noto una trascendencia con cualidad tal que la vía del amparo, en principio, debe tener acogida favorable en el trámite ritual.

En el mismo sentido, más allá de admitir la vía procesal en estudio, ello no importa la procedencia ipso iure de la demanda pretendida. 
La acción de amparo no está destinada a reemplazar los medios ordinarios instituidos para la solución de las controversias ni para obviar los procedimientos administrativos o judiciales.

La sola circunstancia de que se haya planteado un recurso en sede administrativa que se encuentra pendiente de decisión es suficiente para decidir la improcedencia del amparo pues una demanda de esta naturaleza no puede ser utilizada para sustraer la cuestión debatida del conocimiento de la autoridad que interviene en ella por recurso del propio interesado (Fallos 295:35 y 794; 303:419 y 307:178), aunque ello, y en el modo que he propuesto como estudio, no considero como criterio pacífico y absoluto, atento la potencialidad que según las circunstancias de cada caso- de acarrear un perjuicio irreparable.

De allí es que no se advierte el perjuicio irreparable que sufriría, eventualmente, la accionante, de acudir a los remedios ordinarios previstos en la legislación procesal para efectuar el reclamo, que equivoca por esta vía de excepción (art. 20 CPBA y arts. 1, 2 y concs. ley 7166 de la provincia de Buenos Aires).

La Cámara de Apelación en lo Contencioso Administrativo con asiento en La Plata, en la causa "Asociación de padres y amigos del discapacitado "todo para ellos" c/ Municipalidad de Necochea s/ acción de amparo", en trámite ante el Tribunal de Menores No 1 del Departamento Judicial Necochea (expte. no 7625), dispuso: "Es menester, a ese efecto, que el interesado demuestre la ineficacia del sistema procesal en su conjunto, para obtener el resultado perseguido. El carácter subsidiario y de auxilio al ordenamiento adjetivo, que reviste la acción de amparo, lo impone, descartando todo evento que coloque al amparista en la situación común que enfrenta cualquier persona que recurre a la justicia para hacer valer sus derechos."

No ha de entenderse que esa expresión autorice a prescindir de las vías administrativas cuando igualmente sean eficaces, sobre todo en supuestos en que conforme a nuestro ordenamiento jurídico, son previas a las judiciales. De lo contrario, mediante dicho remedio extremo podría, ante la arbitrariedad o ilegalidad de un acto u omisión de algún funcionario, alterarse indebidamente la actividad normal de la administración pública evitando que en ese ámbito se lo corrija, y con ello las instituciones vigentes, con grave riesgo de un virtual desequilibrio entre los poderes del Estado, afectándose el orden establecido por la propia ley fundamental (Conf. este Tribunal en fallo del 25/4/95 en autos Comunidades Indígenas del Pueblo Kolla c/Finca Santiago S.A. y Empresa Ferrameiga S.A. s/acción de amparo; del 25/1/99 en autos Empresa Dal Borgo Construcciones $\mathrm{c} /$ Instituto de Estadísticas y registro de la Industria s/Amparo, y registro de la Industria s/Amparo, y del 29/12/99 en autos Frontera S.A. y otros c/OSECAC s/Acción de Amparo."

Este remedio excepcional no puede ser utilizado para obviar los trámites legales aptos, ni tampoco para urgirlos, (Fallos 311:612) debiendo solo admitirse frente a 
situaciones que revelan la imprescindible necesidad de utilizarlo (Fallo 296:727), extremo que es menester demostrar.

\section{Derechos y Garantías constitucionales}

Es preciso realizar una diferencia entre derechos constitucionales y garantías constitucionales; -

El derecho no es siempre suficiente para su efectiva vigencia o cumplimiento, precisa muchas de un medio que lo haga posible, y he aquí la garantía constitucional; por ello, vienen a ser los medios conducentes para la efectiva realización de los derechos constitucionales. Por ello, la acción amparo viene en resguardo a las normas procesales y procedimentales que, de realizar sus instancias, deviene una violación al cumplimiento de los derechos constitucionales, en caso de rechazar la vía, por incumplimiento formal a la hora de ser incoada.

Comprendo así, la necesidad de estudio respectivo y exhaustivo por los jueces a la hora de responder jurisdiccionalmente sobre la procedencia formal de la acción de amparo que les fuera presentada, ya que, de por sí catalogar sólo que determinados derechos merecen recepción de esta vía y otros, soslayando los posibles perjuicios que se tornarían irreparables, viola otros principios constitucionales, como la garantía de acceso a la justicia, a la igualdad, a la equidad, entre otros.

En lo que respecta a la reforma constitucional del año 1994, se consagra un derecho nuevo que antes era sólo un proceso judicial protector de garantías constitucionales: el amparo; en la redacción de la Carta Magna surge una cuestión que en este trabajo propuse como estudio: ¿Se convierte la vía del amparo en una instancia ordinaria, o sólo procede como excepcionalidad cuando no se puede utilizar para el caso o se culminan los procesos ordinarios administrativos o judiciales?, recordemos a su respecto que la citada norma (art. $43 \mathrm{CN}$ ) prevé que “...toda persona puede interponer acción expedita y rápida de amparo, siempre que no exista otro medio judicial más idóneo...”.

En ello, encuentro que la recepta constitucional del amparo trajo una forma procesal a instancias de sufrir un daño inminente o irreparable en caso de incurrir las vías ordinarias dispuestas con anterioridad, logrando así atención jurisdiccional urgente.

En los autos "Baeza, Aníbal c/ Estado Nacional s/ amparo" se produce una situación especial; interpuesta la acción de amparo, el juez de primera instancia , sin requerir el informe circunstanciado previsto en el artículo $8^{\circ}$ de la Ley $n^{\circ}$ 16.986, entra a considerar el fondo del asunto y rechaza in limine la acción de amparo. Se juzgó a su turno que el rechazo in limine sólo es factible de darse en alguno de los supuestos del artículo $2^{\circ}$ de la Ley $n^{\circ} 16.986$, pero si eso no ocurre y 
la acción es formalmente admisible, y si el juez entra a considerar el fondo de la cuestión traída a debate, debe bajo pena de nulidad, sustanciar la demanda. (32)

En su obra, Gozaíni (33) (Derecho Procesal Constitucional -amparo- editorial Rubinzal-Culzoni), habla dos tipos de protecciones:

* Una, protección inmediata a través de una medida provisional o definitiva, pero donde el proceso continúa; aquí la tutela jurisdiccional opera como medida cautelar dictada en un proceso en trámite, que puede tener cualquiera de las características de la actualmente llamada tutela de urgencia.

* La otra, una protección inmediata que satisface plenamente la petición, y como tal, termina el procedimiento con la sentencia; surge entonces, que la protección se otorga sin oír a la otra parte y con una providencia asimilable a los efectos de la cosa juzgada (la característica es la provisionalidad y la posibilidad de revisión en un juicio pleno).

Se dijo en dicha obra:

La tutela final -sostiene Lorenzetti- está relacionada no tanto con el peligro en la demora sino con la amenaza del daño. De modo que se puede discernir entre un perjuicio derivado del transcurso del tiempo del proceso, que autoriza la cautelar, otro derivado del hecho ilícito. En este último, el tiempo del proceso no es relevante, no es una variable con aptitud para distorsionar el resultado final. Esta protección se puede dar en un espacio procesal que puede ser diferente. Puede tratarse de un juicio ordinario que subordina la cautelar; puede ser un procedimiento precautorio autónomo; se puede dar dentro de un amparo, o bien resolverse en una instancia administrativa con facultades para hacer o actuar la pretensión perseguida (Gozaíni: 462).

En esta corriente, se ha sentado que el amparo novedoso que se incorpora al texto constitucional concreta un derecho de acceso directo a la jurisdicción que impide controvertir sobre la existencia de la vía; pero este debate o excepción puede ser posible si se entiende que existen otras vías más idóneas que mejoren la calidad procesal de la acción directa.

Con lo expuesto, creo que el amparo previsto en la Constitución Nacional es un derecho directamente operativo, que tiene en cuenta el derecho que se tutela antes de la eficacia de la vía elegida; la vista y objetivo primordial radica entiendo- lograr la tan ansiada tutela judicial efectiva

María Mercedes Serra (en obra citada -33- pág. 323) expone que: “...se debe admitir que los procesos constitucionales en general, y el amparo en particular, se diferencian de los procesos ordinarios por la finalidad que persiguen y la materia tratada ${ }_{2}$ y porque constituyen instrumentos procesales diseñados para garantizar la supremacía constitucional y proteger de manera sencilla, rápida y eficaz los 
derechos del hombre consagrados en las cartas fundamentales y en las convenciones internacionales." (lo subrayado me pertenece)

\section{Tutela judicial efectiva}

El amparo, va de la mano de la tutela judicial continua y efectiva, vale decir, se busca mediante dicha vía la protección, procura de derechos y garantías constitucionales, en busca de un estado de derecho y socialmente protector de aquellos.

En el mismo sentido, dicha tutela protege los derechos y garantías en todo procedimiento administrativo y proceso judicial tanto de los individuos, como de los grupos sociales y de la comunidad toda que se ha visto varias veces vulnerada y desamparada.

Refiriendo a la nueva Ley de Amparo de la provincia de Buenos Aires ( ${ }^{\circ}$ 13.928), Gabriela García ha dicho que la misma resulta propicia para una nueva provincia que busca mejorar y crecer junto a sus instituciones, llevándola hacia la tutela judicial y administrativa continua y efectiva. La nueva ley de amparo se ha encargado de generar el sendero adecuado (RAP, 2010: 81).

\section{Legitimación activa (a modo enunciativo)}

El ejercicio de la legitimación activa de la acción de amparo se encuentra recepto en el artículo 43 de la Constitución Nacional, y reza:

1. Toda persona física o jurídica que se encuentre afectada en sus derechos o intereses individuales o derechos de incidencia colectiva; -

2. Las asociaciones que sin revestir el carácter de personas jurídicas justifique la exhibición de sus estatutos que no contrarían una finalidad de bien público; -

3. Defensor del pueblo. (artículo $86 \mathrm{CN}$ ).

\section{Recepción de la última parte del artículo 43 de la Constitución Nacional:}

"Declaración de inconstitucionalidad de la norma al caso concreto."

Culminando, no debo olvidar en el presente trabajo, más allá del encuadre procesal al amparo como vía idónea y admisible que propuse, la actual redacción del artículo 43 de la Constitución Nacional ha removido el obstáculo que representaba el inc. $\mathrm{d}$, artículo $2^{\circ}$ de la Ley $\mathrm{n}^{\circ} 16.986$, al habilitar por vía de acción de amparo, la declaración de inconstitucionalidad de la norma en que se funde el acto u omisión lesivos. Ello, amén de señalar que, aun antes de la recepción constitucional, la jurisprudencia mayoritaria se había pronunciado en favor de la misma, sobre la base de que esta restricción no podía ser entendida de 
manera absoluta, pues equivaldría a destruir la esencia misma de la institución del amparo, inspirada en el propósito de salvaguardar los derechos sustanciales de las personas cuando no existen otros remedios capaces a ese fin.

\section{Conclusión abordada}

Con el desarrollo de la materia en estudio, destaco la esencia de la acción de amparo, ponderada tanto por la jurisprudencia de la Corte Nacional y doctrina resonante.

Vale decir, la transcripción que realiza nuestra Constitución Nacional refleja que estamos ante un acción expedita y rápida, siempre que no exista otro medio judicial más idóneo (artículo 43);

Con ello, y meritando el análisis descripto, entiendo que con el transcurrir del tiempo, y del conjunto fáctico de acciones amparo presentadas ante la justicia, se ha limitado su recepción procesal atento ponderar en cada caso que la misma debe presentar una situación excepcional, especial, y que la viabilidad de una acción ordinaria tendría como consecuencia una daño irreparable por la ritualidad de aquellos, por ejemplo, en plazos, traslados, producción de prueba, alegatos, etc..

De modo que, más allá de explicar dos corrientes bien diferenciadas en el análisis procesal del amparo, entiendo que debemos -en conjunto socialcomprender la esencia que dio el constituyente al artículo $43 \mathrm{CN}$, y recabar los antecedentes nacionales e inferiores para concluir que la situación que plantea el amparista debe comparecerse con un estado de necesidad que requiera una decisión jurisdiccional urgente, demostrando -si correspondiere- que instar las vías ordinarias administrativas o judiciales, pueda ocasionarle daño irreparable.

Por lo cual, compartiendo ciertos parámetros de ambas corrientes desarrolladas, resalto que: "todos" tenemos la tarea y responsabilidad de que -en cada casoobservar las características que la norma precepta para la viabilidad del amparo, esto es, cuando el objeto pretendido sea urgente, excepcional, especial, y necesite una decisión con las mismas características, merece instar la vía de amparo en estudio; cuando suceda lo contrario, es decir, la posibilidad que otorga la norma de incurrir a otras vías idóneas para dicho objeto y ello no ocasione daño irreparable, corresponde rechazar la vía expedita y rápida del artículo $43 \mathrm{CN}$.

Por lo que, esta garantía receptada primeramente por la jurisprudencia, luego por la ley y finalmente por la Constitución Nacional, vino a establecer una "opción", un "remedio", una "vía especial", un "recurso" ante situaciones que requieran una pronta expedición de la justicia, ello, como vía procesal pertinente por sobre las instancias ordinarias que la norma reza para cada caso.

De modo que, como resultado de estudio e investigación, concluyo que dentro del marco de una acción como la de amparo, debe existir por parte de quien la inste -y demostrar en consecuencia- un estado de necesidad que requiera 
respuesta inmediata del juzgador, por padecer un derecho constitucional que le ha sido violado, valiéndose así de una acción que le posibilite soslayar de procedimientos administrativos y/o judiciales ordinarios, atento que la instancia por ante ellos le haría un daño irreparable, por lo que, la acción expedita y rápida que prevé la Constitución Nacional y leyes, deviene de irreprochable aplicación.

No quiero olvidar, y destacar, que desde el punto de vista conceptual, amparar significa tutelar, o bien valerse del apoyo de alguien o algo previsto para lograr determinada protección a sus derechos;

Viene del latín anteparare que significa prevenir, lo que tiene consonancia con el texto constitucional cuando recepta "...en forma actual o inminente, restrinja, altere o amenace..."; ergo, el objetivo impuesto radica en la necesidad de, prevenir un daño, o bien dar una respuesta -en el marco de un proceso expedito y rápidoante una petición concreta que persiga el cumplimiento o la no violación de un derecho constitucional.

Por último, quiero traer lo dicho por el autor Bidart Campos, quien opina que el juez puede y debe realizar un somero examen de admisibilidad de la demanda (en la acción de amparo claro está), y si prima facie dicho estudio desembocara en una conclusión de inadmisibilidad, debería rechazarse la petición iniciada, de todas maneras, tal análisis debe realizarse con "mucha cautela y prudencia." Lo subrayado me pertenece (Campos, 1968: 200). 


\section{Bibliografía}

Bidart Campos (1968). Régimen legal, Ediar. Antiguos, Buenos Aires.

CASsagne, J.C. (2007). Amparo, Medidas Cautelares y otros procesos urgentes en la Justicia Administrativa. Primera Edición. Buenos Aires.

CÁmARA de APELACIÓn EN lO CONTENCIOSO ADMINISTRATIVO CON ASIENTO EN SAN MARTíN, provincia de Buenos Aires, en causa No 363/05, caratulada "Emigen S.A. c/Municipalidad de La Matanza s/amparo (301)".

CÁmara Federal Resistencia (1984). "Asociación de Trabajadores de la Universidad del Nordeste c. Resolución 4/84 de la Universidad Nacional del Nordeste”, LL, 1985-B-91.

Corte Suprema Justicia de la Nación (1990) "Peralta, Luis A. y ot. C. Gobierno Nacional”, JA, 1991-II-556.

(2000). "Entre Ríos, Provincia de y otro c/ Estado Nacional -Secretaría de Energía-s/ Acción de Amparo”, Fallos: 323: 1825.

corpus”, Fallos 239:459.

(1957). "Siri, Angel s/ interpone recurso de hábeas

(1958). "Kot, Samuel S.R.L s/ recurso de hábeas corpus”, Fallos 241:291.

Corte Nacional Fed. Contencioso Administrativo. (2003) "Iamp Medisur S.A. c/ Poder Ejecutivo Nacional- Ministerio de Obras y Servicios Públicos", LL, 2000-B-280; DJ, 2000-2-254]. (Juicio de amparo. Omar Luis Díaz Solimine. Volumen 13. Hammulabi, Jose Luis Depalma, editor. $1^{\circ}$ edición, Buenos Aires).

DOCtrina Suprema CORTE Buenos Aires (2004) "Usuarios y Consumidores en Defensa de sus Derechos Asociación Civil”, sent. de 22-IX-2004. Mar del Plata. Cámara de Apelación en lo Contencioso Administrativo con asiento en dicha ciudad,sentencia en la causa A-318-AZ0.

Doctrina de Fallos: 301: 801; 303: 419 entre muchos otros, reiterada por la CSJN en autos "Villar, Carlos Alfredo c/ Banco Central de la República Argentina s/ amparo", del 23-2-95).

Gelli M.A. (2008). Constitución de la Nación Argentina, comentada y concordada. La Ley. Cuarta edición. Tomo I. Buenos Aires.

GozAInI, A. (2002). Derecho Procesal Constitucional. Amparo. Doctrina y jurisprudencia. Ed Rubinzal. Buenos Aires.

Morello, A. M. (1994) " La primera sentencia sobre amparo a la luz de la Constitución reformada" Jurisprudencia Argentina 1994-IV-673 Ley 1995-E, 1330. 
Moreno G. R. (2008). Constitución de la Provincia de Buenos Aires. Comentada, concordada y con notas de jurisprudencia. Librería Editora Platense. La Plata

Peyrano, J. (1997). Medidas Autosatisfactivas. Rubinzal Culzoni. Buenos Aires. Argentina.

Revista RAP PROVINCIA DE Buenos Aires (2009). "Actualidad jurídica provincial y municipal bonaerense”. Doctrina. Año VII. Nros. 81/82.

Supremo Tribunal de Justicia de SANTiago del Estero (1990). "Morini c/ Instituto de Seguridad Social", en Jurisprudencia Temática - Acción de Amparo, por Cristella Seró, en "Amparo. Habeas Data. Habeas Corpus - I", de la "Revista de Derecho Procesal", Rubinzal-Culzoni editores, n 4, Santa Fe.

Sagües N. P (2007). Derecho Procesal Constitucional. Acción de Amparo. 5 edición. Editorial Astrea. Buenos Aires.

VALlEFIN C. (2006) "Importancia y jerarquía constitucional de las medidas cautelares". Temas de Derecho Administrativo en honor la Prof. Agustín A. Gordillo, Ed. Librería Editorial Platense. 